\section{AIDS virus antibody in polytransfused dialysis patients vaccinated against hepatitis B}

Patients receiving long term haemodialysis are at increased risk of hepatitis $B$ infection. Given the similar transmission routes of hepatitis B virus and the virus of the acquired immune deficiency syndrome (AIDS) it is surprising that no seroprevalence data on infection with lymphadenopathy associated virus/human T cell lymphotropic virus type III (LAV/HTLV-III) in dialysis centres have been published. We present data from 18 haemodialysis centres in Belgium, where we surveyed all patients who had received at least three doses of hepatitis B vaccine. These centres had had a high incidence of hepatitis $B$ infection before vaccination. ${ }^{1}$

\section{Patients, methods, and results}

At the end of 1985 serum samples were obtained from 729 patients receiving haemodialysis $(335(46 \%)$ men, $394(54 \%)$ women). These patients received three to nine (mean $4 \cdot 2$ ) doses of plasma derived hepatitis $B$ vaccine, some beginning in $1981 .{ }^{1}$ They had been dialysed in 18 centres in Belgium for an average of 37 months. Pasteur vaccine (six lots) had been given to 488 patients (67\%); CLB (Centraal Laboratorium voor de Bloedtransfusie, Dutch Red Cross) vaccine (two lots) to $146(20 \%)$; MSD (Merck Sharp and Dohme) vaccine (one lot) to $29(4 \%)$; and an assortment of the above vaccines to the others. About $90 \%$ of patients had received blood transfusions. In $1981,46 \%$ of patients were transfused over six months, ${ }^{1}$ and this practice had essentially been maintained.

Screening for anti-LAV/HTLV-III by the Abbott enzyme linked immunosorbent assay gave a positive finding in 33 patients $(4.5 \%)$ and the result remained positive on repeat testing in $17(2 \cdot 3 \%)$. In no case detected by screening could the result be confirmed by immunofluorescence, Western blot, or the Wellcome competitive enzyme linked immunosorbent assay, and results were also negative with the new Abbott recombinant envelope/core competitive confirmatory enzyme linked immunosorbent assay. Most false positive results could be explained by cross reactivity in the Abbott screening assay of antibody against lymphocyte (HLA) components elicited by transfusion.

\section{Comment}

Our findings in polyvaccinated, polytransfused patients show the complete safety from AIDS of all hepatitis B vaccines sold in Europe, regardless of methods of manufacture. They also show that blood transfusion in Belgium has remained very safe. The spread of the AIDS virus in Belgium has been late and slow, despite the many diagnoses of AIDS in visitors to Belgium. Since 1982-3 risk groups have been barred from donating blood, and since August 1985 all donations have been screened for antibody. According to a provisional estimate of the Belgian AIDS Commission, about five in 100000 donors in 1985 were true positives for the antibody.

The evidence that patients with renal insufficiency seroconvert and may develop symptoms of AIDS virus infection comes from patients grafted with infected kidneys ${ }^{3.5}$ and not from those exposed either to occasional true seropositive subjects who enter dialysis programmes or to blood transfusions. No proof of transmission of the AIDS virus during haemodialysis has been published, which is in sharp contrast with the easy spread of hepatitis B virus in this setting.

We thank the Leuven Collaborative Group on Renal Transplantation for collecting the serum samples.

1 Desmyter J, De Groote G, Colaert J, et al. Efficacy of heat-inactivated hepatitis B vaccine in haemodialysis patients and staff. Lancet 1983 ;i: $1323-8$.

2 Kühnl P, Seidl S, Holzberger G. HLA DR4 antibodies cause positive HTLV-III antibody ELISA results. Lancet 1985 ; i:1222-3.

3 Prompt CA, Reis MM, Grillo FM, et al. Transmission of AIDS virus at renal transplantation. Lancet 1985 ;ii: 672.

4 L'Age-Stehr J, Schwarz A, Offermann G, et al. HTLV-III-infection in kidney transplan recipients. Lancet 1985 ;ii: 1361

5 Neumayer $\mathrm{H}-\mathrm{H}$, Wagner K, Kresse S. HTLV-III antibodies in patients with kidney transplants or on haemodialysis. Lancet 1986;i:497.

(Accepted 30 June 1986)

Rega Institute and University Hospitals, University of Leuven, B-3000 Leuven, Belgium

JAN DESMYTER, MD, PHD, professor of virology

MARTIN REYNDERS, MT, chief technologist

PATRICK GOUBAU, MD, senior staff fellow

Correspondence to: Professor Desmyter.

\section{Renal cell carcinoma: blood transfusion and survival}

Data indicating that blood transfusion may be a significant risk factor in the prognosis of colonic cancer were reported in 1982 and $1985 . .^{2}$ No causal association was claimed for this observation, but it is thought that homologous blood transfusion may cause immunosuppression, which might explain the improved survival of kidney grafts after transfusion. ${ }^{3}$ We performed a retrospective analysis of transfusions and death due to recurrence in patients with surgically curable renal cell carcinoma.

\section{Patients, methods, and results}

We examined the records of patients who had undergone nephrectomy for renal cell carcinoma during 1975-85. Age, sex, presenting symptoms, date of operation, site of tumour, tumour stage, haemoglobin concentration and packed cell volume on admission, details of blood transfusions, duration of follow up, use of chemotherapy or irradiation, and recurrence of tumour or death were recorded. We selected all patients considered to be potentially curable by surgery and therefore excluded (i) those who presented with metastases; (ii) those found at operation to have nodal disease; and (iii) those whose carcinoma was beyond stage pT 3 or V1. A total of 80 patients met these criteria.

A binary variable was used to indicate whether each patient had or had not been given a blood transfusion, as the death rate among patients who had received transfusions seemed to be constant regardless of the timing of the transfusion, the number of transfusions given, and the total number of units transfused. Altogether 55 patients had received perioperative blood transfusion.

We used the tumour classification of the International Union Against Cancer (1978). Fourteen patients had stage pT1 disease, 41 stage pT2, and 25 stage pT3 The incidence of transfusion in these three staging groups was $21 \%(3 / 14), 76 \%$ $(31 / 41)$, and $84 \%(21 / 25)$ respectively.

Owing to the inexact nature, timing, and measurement of recurrence and the fact that recurrence inevitably led to death in these patients we used survival time rather than the time to recurrence in the analysis. Distributions of the survival times were estimated for patients who had received transfusions and those who had not using the Kaplan-Meier product limit method. ${ }^{4}$ Those who died from other causes and those who survived until the end of the study were treated as censored data (figure). The difference in the survivor functions was significant using the Mantel-Cox statistic $(p=0 \cdot 04)$.

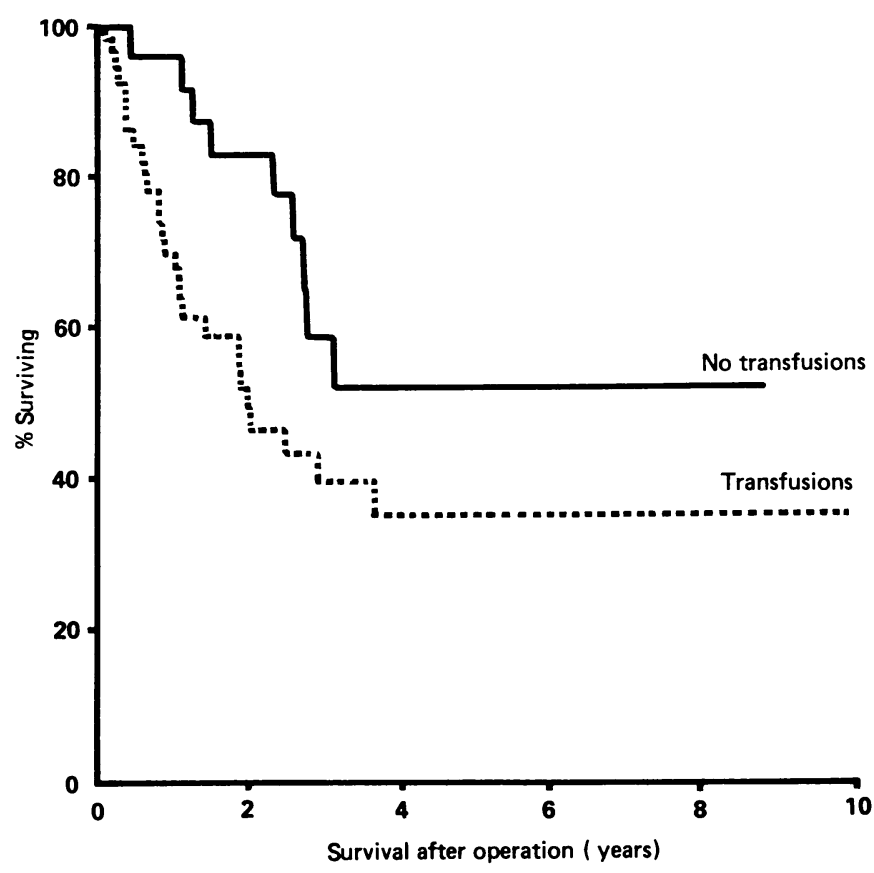

Survival of patients who had and had not received transfusions.

A series of Cox proportional hazards models were fitted using all baseline factors except transfusion state as covariates. ${ }^{5}$ Only the stage (pT) of tumour was a significant factor $(p<0 \cdot 05)$. When transfusion state was added to the proportional hazards model as an additional covariate the log likelihood was increased by $0 \cdot 30$. The test statistic, derived as $2 \times 0.30$ and compared with a $\chi^{2}$ distribution with one degree of freedom, was not significant. We therefore concluded that blood transfusion has no significant effect on survival time once the stage (pT) of tumour has been accounted for. 